\title{
Crop Response based Assessment of Limiting Nutrients using Site Specific Nutrient Management for Yield Maximization in Vertisols of Bemetara District of Chhattisgarh, India
}

\author{
Neha Sahu*, V.N. Mishra, L.K. Srivastava and Gaurav Jatav \\ Department of Soil Science and Agricultural Chemistry, College of Agriculture, \\ IGKV, Raipur - 492013, India \\ *Corresponding author
}

\begin{tabular}{|l|}
\hline Ke y w or d s \\
SSNM, Omission \\
plot technique, \\
Yield limiting \\
nutrients.
\end{tabular}

\section{A B S T R A C T}

A pot culture experiment was conducted in the green house of the Department of Soil Science and Agricultural Chemistry, College of Agriculture, IGKV, Raipur during kharif season 2015 to study the crop response based assessment of limiting nutrients using site specific nutrient management for yield maximization in Vertisols of Bemetara district of Chhattisgarh. The treatments constituted with application of all nutrients applied at optimum level known as SSNM dose while in others, one of the nutrient elements from all the nutrient treatments was omitted. Total 11 treatments were tested with rice (MTU-1010) as a test crop, laid out in CRD with three replications. Grain and straw yields of rice was significantly reduced with the omission of $\mathrm{N}, \mathrm{P}$, and $\mathrm{S}$ in comparison to the treatment receiving all the nutrients (SSNM). The yield reductions were more pronounced with $\mathrm{N}$ and $\mathrm{P}$ omission as 54.76 and $44.73 \%$, respectively. The per cent reduction in rice yields recorded as $11.63 \%$ with $\mathrm{S}$ omission, $8.99 \%$ with $\mathrm{Zn}$ omission and $6.51 \%$ with $\mathrm{B}$ omission treatments. Based on the performance of rice crop during Kharif season, the yield limiting nutrients identified were in the order of $\mathrm{N}>\mathrm{P}>\mathrm{S}>\mathrm{Zn}>\mathrm{B}$. These limiting nutrients were tested on farmer's fields with wheat crop during Rabi season, 2015-16 where bulk soil samples were collected for pot culture study. The limiting nutrients applied in optimum doses (SSNM) as $\mathrm{N}-150, \mathrm{P}_{2} \mathrm{O}_{5}-100, \mathrm{~K}_{2} \mathrm{O}-80, \mathrm{~S}-45, \mathrm{~B}-3$ and $\mathrm{Zn}-7.5$ $\mathrm{kg} / \mathrm{ha}$. The wheat yield was recorded $29 \%$ higher as compared to the farmer's fertilizer practice (80:58:38 kg N: $\mathrm{P}_{2} \mathrm{O}_{5}: \mathrm{K}_{2} \mathrm{O}$ ).

\section{Introduction}

The site-specific nutrient management (SSNM) approach was developed in Asian rice-producing countries through partnerships of the Irrigated Rice Research Consortium (IRRC). It emphasizes 'feeding' rice with nutrients as and when needed. SSNM strives to enable farmers to dynamically adjust fertilizer use to optimally fill the deficit between the nutrient needs of a high-yielding crop and the nutrient supply from naturally occurring indigenous sources such as soil, organic amendments, crop residues, manures, and irrigation water. The SSNM approach does not specifically aim to either reduce or increase fertilizer use. Instead, it aims to apply nutrients at optimal rates and times to achieve high yield and high efficiency of nutrient use by the rice crop, leading to high cash value of the harvest per unit of fertilizer invested. Among the various cropping 
systems, rice based cropping systems are the predominant systems in India. Managing the variability in soil nutrient supply that has resulted from intensive rice cropping is one of the challenges for sustaining and increasing rice yield in India. The use of plant nutrients in a balanced manner is the prime factor for efficient fertilizer program. Balanced nutrient use ensures high production level and helps to maintain the soil health and ensures sustainable agriculture. Deficiency of some micro- and secondary nutrients is one of the major causes for stagnation in crop productivity. Exploitive nature of modern agriculture involving use of high analysis $\mathrm{N}$, $\mathrm{P}$ and $\mathrm{K}$ fertilizers, free from micronutrients as impurities, limited use of organic manures and restricted recycling of crop residues are some important factors having contributed towards accelerated exhaustion of secondary and micronutrients from soil. At several places, normal yield of crops could not be achieved despite balanced use of NPK due to micronutrient deficiency in soils (Sakal, 2001).

Adequate supply of plant nutrients decides optimum productivity of any cropping system. Even if, all other factors of crop production are in the optimum, the fertility of a soil largely determines the ultimate yield (Sekhon and Velayutham, 2002). Application of supplemental nutrients is required if the soil does not supply sufficient nutrients for normal plant development and optimum productivity. Fertilizer is one of the most important sources to meet this requirement. Indiscriminate use of fertilizers, however, may cause adverse effect on soils and crops both regarding nutrient toxicity and deficiency either by over use or inadequate use (Ray et al., 2000). Diagnostic techniques including identification of deficiency symptoms, soil and plant analysis and biological tests are helpful in determining specific nutrient stresses and quantity of nutrients needed to optimize the yield (Havlin et al., 2007). Soil fertility evaluation, thus, is the key for adequate and balanced fertilization in crop production.

Chhattisgarh State has four major soils type i.e. Entisols, Inceptisols, Alfisols and Vertisols. Almost all soils are deficient in nitrogen and phosphorus and medium to high in potassium. Zinc deficiency is also reported in some patches of Alfisols and Vertisols of this region. In view of continuous use of sulfur free complex fertilizers, chances of increase in $\mathrm{S}$ deficiency are likely. In addition to this limitation, low fertilizer efficiency, inadequacy of current fertilizer recommendations and the ignorance of nutrients other than $\mathrm{N}, \mathrm{P}$, and $\mathrm{K}$ may limit crop production. In view of continuous use of high analysis fertilizer, multiple nutrient deficiencies are likely. High crop yields can only be achieved by correcting such deficiencies. Site specific nutrient management is of utmost importance for obtaining high yields on sustainable basis.

\section{Materials and Methods}

A pot culture study was undertaken in the green house of the Department of Soil Science and Agricultural Chemistry, College of Agriculture, IGKV, Raipur during kharif season 2015 to study Crop response based assessment of limiting nutrients using site specific nutrient management for yield maximization in Vertisols of Bemetara district of Chhattisgarh. For this purpose, representative Vertisol field of farmer from Bargaon village of the Berala block, district Bemetara was selected based on intensive cropping followed since last 20 years. Surface soil sample was collected in bulk for pot culture experiment. The objectives of the study were to identify the specific nutrients which limit the crop yield through rice response using nutrient omission technique in 
kharif season, and to demonstrate the optimum use of identified limiting nutrients and it's comparison with farmer's fertilizer practice with wheat crop in Rabi season.

The treatments constituted with application of all nutrients applied at optimum level and called as SSNM dose/All nutrients applied, omission of each nutrient from SSNM dose using nutrient omission technique to identify the limiting nutrients. Total 11 treatments were formulated with application of nutrients $(\mathrm{N}, \mathrm{P}, \mathrm{K}, \mathrm{S}, \mathrm{Fe}, \mathrm{Mn}, \mathrm{Cu}, \mathrm{B}, \mathrm{S}$ and $\mathrm{Mo}$ ) in optimum level and sequentially each nutrient was omitted from all nutrients applied (SSNM). The processed and uniformed soil samples were filled in cemented pots @ $10 \mathrm{~kg}$ and nutrients as specified above were applied through different sources taking care to avoid any precipitation during solution mixing and application. The optimum doses of nutrients were fixed in $\mathrm{kg} / \mathrm{ha}$ as $\mathrm{N}-150, \mathrm{P}_{2} \mathrm{O}_{5}-44, \mathrm{~K}_{2} \mathrm{O}$ - 66, S - 45, Fe - 20, Mn - 15, Cu - 7.5, Zn 7.5, B - 3 and Mo - 0.75 for SSNM dose. Rice (MTU-1010) was taken as test crop laid out under CRD (Completely Randomized Block Design) with three replications.

The optimum use of identified limiting nutrients was demonstrated on farmer's field with wheat crop during Rabi season 2015-16 and compared with farmer's fertilizer practice. Three seedlings of MTU-1010 variety of rice were planted in three hills in each pot and water level was maintained at $3 \mathrm{~cm}$ throughout the crop season. The initial status of soil $\mathrm{pH}$ was 7.6, CEC - $41.31 \mathrm{Cmol} \mathrm{kg}^{-1}$, low in organic $\mathrm{C}\left(4.5 \mathrm{~g} \mathrm{~kg}^{-1}\right)$, alkaline $\mathrm{KMnO}_{4}-\mathrm{N}\left(218 \mathrm{~kg} \mathrm{ha}^{-1}\right)$, Olsen $\mathrm{P}(12.64 \mathrm{~kg}$ $\left.\mathrm{ha}^{-1}\right), \mathrm{CaCl}_{2}$ extractable $\mathrm{S}\left(22.61 \mathrm{~kg} \mathrm{ha}^{-1}\right)$, high in amm. Acetate extractable K $(563 \mathrm{~kg}$ $\left.\mathrm{ha}^{-1}\right)$ and higher exchangeable $\mathrm{Ca}(6325 \mathrm{~kg}$ ha-1) and $\mathrm{Mg}$ (966 kg ha-1). Available S status was at marginal $\left(22.61 \mathrm{~kg} \mathrm{ha}^{-1}\right)$. The Fe and $\mathrm{Mn}$ level in the soil was sufficient whereas $\mathrm{Zn}, \mathrm{B}$ and $\mathrm{Cu}$ were near to critical level.

\section{Results and Discussion}

The mean grain and straw yields of rice (Table 1) were significantly affected with different treatments applied. Omission of $\mathrm{N}$ and $\mathrm{P}$ reduced the grain and straw yields of rice significantly over the treatment that received all nutrients (SSNM). Highest yield $(30.40 \mathrm{~g} / \mathrm{pot})$ was recorded in the treatment of Mn omitted from SSNM which was at par with those of other treatments received all nutrients (SSNM) and omitted with $\mathrm{K}, \mathrm{Fe}, \mathrm{S}$, $\mathrm{Cu}, \mathrm{Zn}, \mathrm{B}$, Mo from SSNM treatment. Omission of $\mathrm{N}$ reduced the grain yield by $54.76 \%$ while $\mathrm{P}$ omission caused a yield reduction of $44.73 \%$. The per cent reduction in rice yields under different nutrients omitted pots were in the order of $(54.76 \%) \mathrm{N}>$ $(44.73 \%) \quad \mathrm{P}>(11.63 \%) \quad \mathrm{S}>(8.99 \%) \mathrm{Zn}>$ (6.51\%) B (Fig. 1). Mean straw yields of rice in $\mathrm{K}, \mathrm{Fe}, \mathrm{Cu}, \mathrm{Zn}, \mathrm{B}$ and $\mathrm{Mo}$ omitted from SSNM treatment did not vary significantly and were statistically at par. Straw yields of rice in $\mathrm{N}, \mathrm{P}$ and $\mathrm{S}$ omitted pots showed significantly lower yield from all other treatments including SSNM.

Results clearly show that $\mathrm{N}$ is the most critical nutrient that affects the grain yield considerably followed by P. Omission of all other nutrients did not indicate yield reduction significantly. However, omission of S, Zn and $\mathrm{B}$ nutrients reduced the yields by $11.64,8.98$ and $6.49 \%$, respectively. Considerable reductions in grain yield due to these nutrients might be due their insufficient/marginal level. Similar results have also been reported by Bhuiyan et al., (1986), Suriya Arunroj et al., (2000) and Segda et al., (2005).

Oxidation loss of organic matter under tropical climatic conditions results in low organic carbon (Singh et al., 2000). Since organic matter content is an indicator of available nitrogen status of soils, the soils of the area are also dominantly low in respect of 
available nitrogen. The soil under study was inherently low in available P (Table 1) and hence the omission of $\mathrm{P}$ caused more reduction in yield. On the basis of yield performance, the next elements which limited the yield was $\mathrm{S}$ followed by $\mathrm{Zn}$ and B. Yield reduction due to $S$ omission may be attributed to less supply of $S$, since the available $S$ in this soil was in the lower margin of medium category (22.61 kg ha ${ }^{-1}$ ). Continuous use of $\mathrm{S}$ free fertilizers like DAP and others may also be one of the possible reasons for lowering the $\mathrm{S}$ status in soil and caused yield reduction (Biswas et al., 2004). Similarly, Zn omitted pots may be attributed to low availability of $\mathrm{Zn}$ upon flooding because of formation of sparingly soluble sulphides and carbonates under anaerobic conditions (Yoshida et al., 1971). The marginal level of $\mathrm{Zn}$ in the soil under study due to continuous crop removal may also be a reason for lowering the yield.

Higher adsorption and immobilization of $\mathrm{S}$ (Tiwari et al., 2006) might have resulted in lower yield. With respect to B omission treatment, yield reductions may be attributed to reduced availability of $\mathrm{B}$ due to formation of Ca-borate and B-silicate (Sharma et al., 2003) and low soil status. On the basis of yield performance, the yield limiting nutrients in Vertisols of Bemetara district may be put in the order of $\mathrm{N}>\mathrm{P}>\mathrm{S}>\mathrm{Zn}>\mathrm{B}$.

The mean total N, P and K uptake (Fig. 2) by rice were significantly affected with application of different treatments. Highest N uptake (498 mg/pot) was observed in $\mathrm{Mn}$ omission treatment followed by (488 mg/pot) treatment receiving all the nutrients (SSNM). $\mathrm{N}$ omission treatment recorded lowest (230 $\mathrm{mg} / \mathrm{pot}) \mathrm{N}$ uptake followed by $\mathrm{P}$ and $\mathrm{S}$ omitted treatments which were significantly differed among them. Average $\mathrm{P}$ uptake by rice was significantly affected with different treatments application. Lowest $\mathrm{P}$ uptake (47 $\mathrm{mg} / \mathrm{pot}$ ) was observed in $\mathrm{N}$ omitted treatment followed by $\mathrm{P}$ omitted (49 $\mathrm{mg} / \mathrm{pot}$ ), $\mathrm{Zn}$ omitted $(82 \mathrm{mg} / \mathrm{pot})$ and $\mathrm{S}$ omitted (81 $\mathrm{mg} / \mathrm{pot})$ treatments. These treatments were statistically significant. $\mathrm{P}$ uptake by rice in $\mathrm{Fe}$, $\mathrm{Mn}, \mathrm{K}, \mathrm{Cu}, \mathrm{Mo}$, and $\mathrm{B}$ omitted treatments along with SSNM were statistically at par with each other.

Table.1 Grain and straw yields (g/pot) of rice (MTU-1010) in relation to Different treatments in Vertisol

\begin{tabular}{|c|c|c|c|}
\hline S. No. & Treatments & Grain yield & Straw yield \\
\hline 1 & All $($ SSNM) & $29.49 \mathrm{ab}$ & $30.97 \mathrm{a}$ \\
\hline 2 & All $-\mathrm{N}$ & $13.34 \mathrm{c}$ & $18.84 \mathrm{~d}$ \\
\hline 3 & All $-\mathrm{P}$ & $16.30 \mathrm{c}$ & $21.52 \mathrm{~d}$ \\
\hline 4 & All $-\mathrm{K}$ & $29.38 \mathrm{ab}$ & $30.35 \mathrm{ab}$ \\
\hline 5 & All $-\mathrm{S}$ & $26.06 \mathrm{~b}$ & $26.53 \mathrm{c}$ \\
\hline 6 & All - Fe & $28.79 \mathrm{ab}$ & $31.93 \mathrm{a}$ \\
\hline 7 & All $-\mathrm{Mn}$ & $30.40 \mathrm{a}$ & $32.06 \mathrm{a}$ \\
\hline 8 & All $-\mathrm{Cu}$ & $29.00 \mathrm{ab}$ & $30.83 \mathrm{a}$ \\
\hline 9 & All - Zn & $26.84 \mathrm{ab}$ & $26.99 \mathrm{bc}$ \\
\hline 10 & All $-\mathrm{B}$ & $27.57 \mathrm{ab}$ & $28.81 \mathrm{abc}$ \\
\hline 11 & All - Mo & $29.10 \mathrm{ab}$ & $31.35 \mathrm{a}$ \\
\hline & CD at 5\% & $\mathbf{3 . 6 2}$ & $\mathbf{3 . 5 2}$ \\
\hline
\end{tabular}

In a column, means with a common letter are not significantly different by DMRT test. 


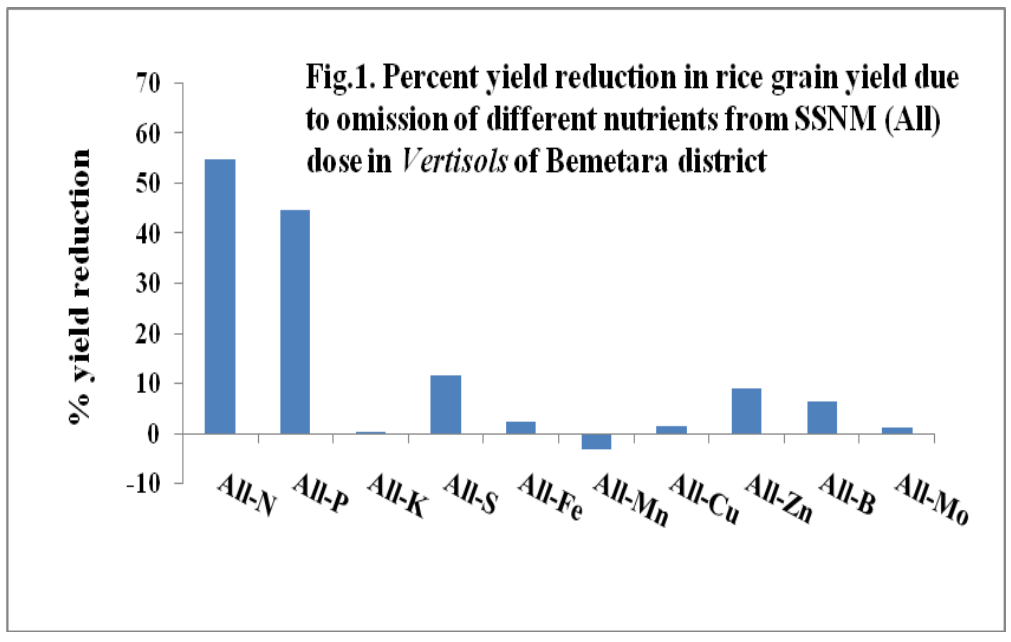

Fig.2 Total uptake of $\mathrm{N}, \mathrm{P}$ and $\mathrm{K}(\mathrm{mg} / \mathrm{pot})$ in rice in relation to different treatments

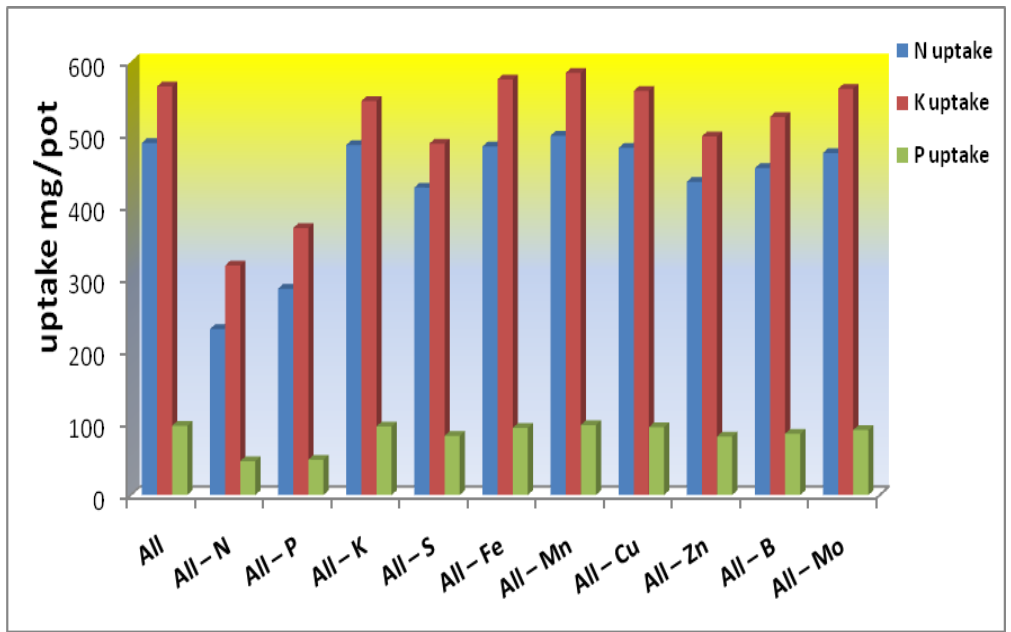

Fig.3 Total uptake of $\mathrm{Ca}, \mathrm{Mg}$ and $\mathrm{S}(\mathrm{mg} / \mathrm{pot})$ in rice in relation to different treatments

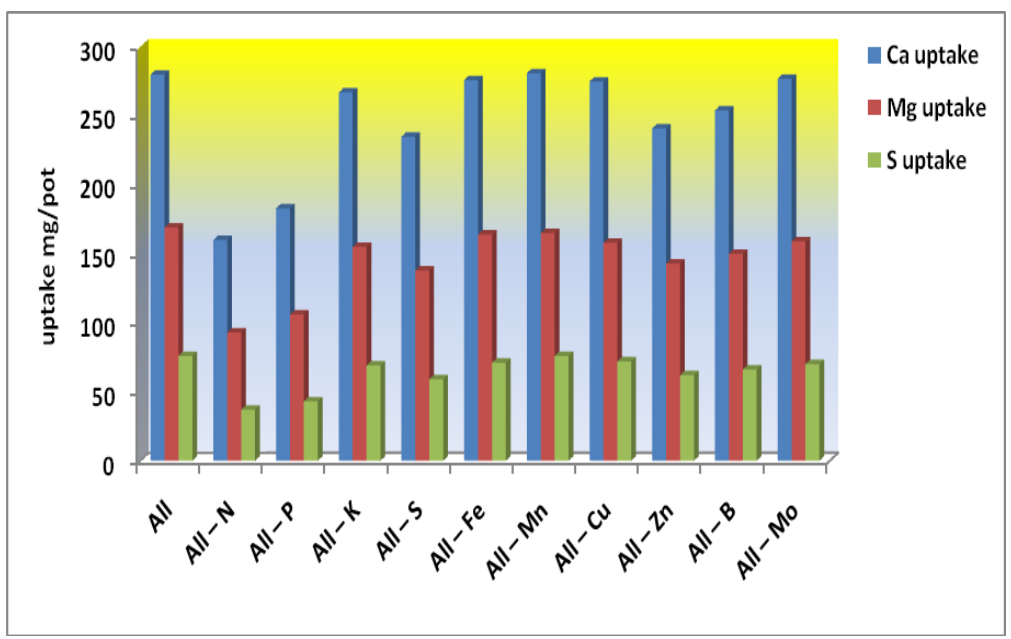


Fig.4 Total uptake of Fe and Mn of rice (mg/pot) in relation to different

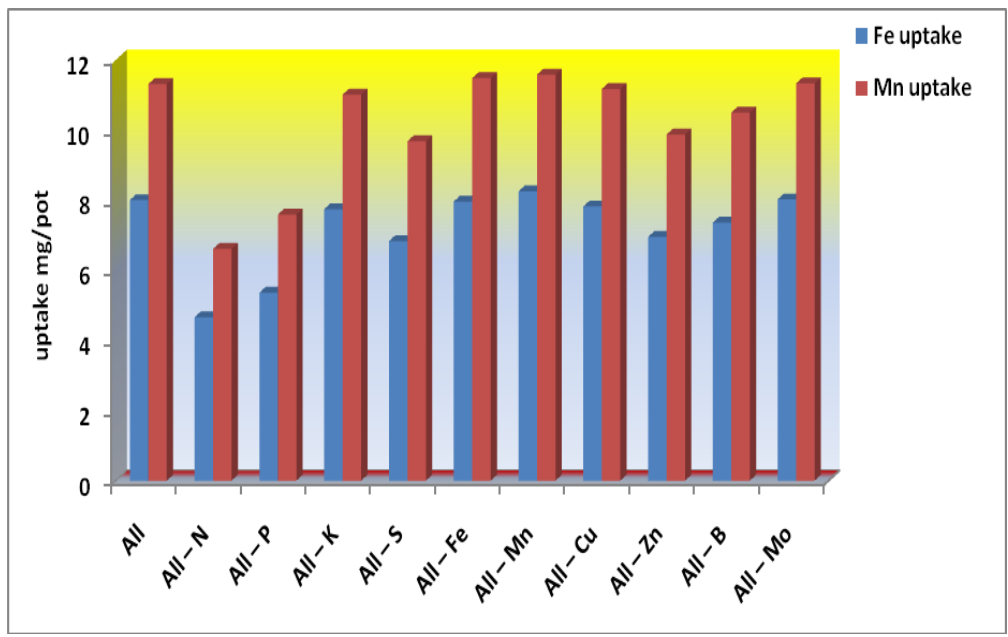

Fig.5 Total uptake of $\mathrm{Zn}, \mathrm{Cu}$ and $\mathrm{B}$ of rice $(\mathrm{mg} / \mathrm{pot})$ in relation to different

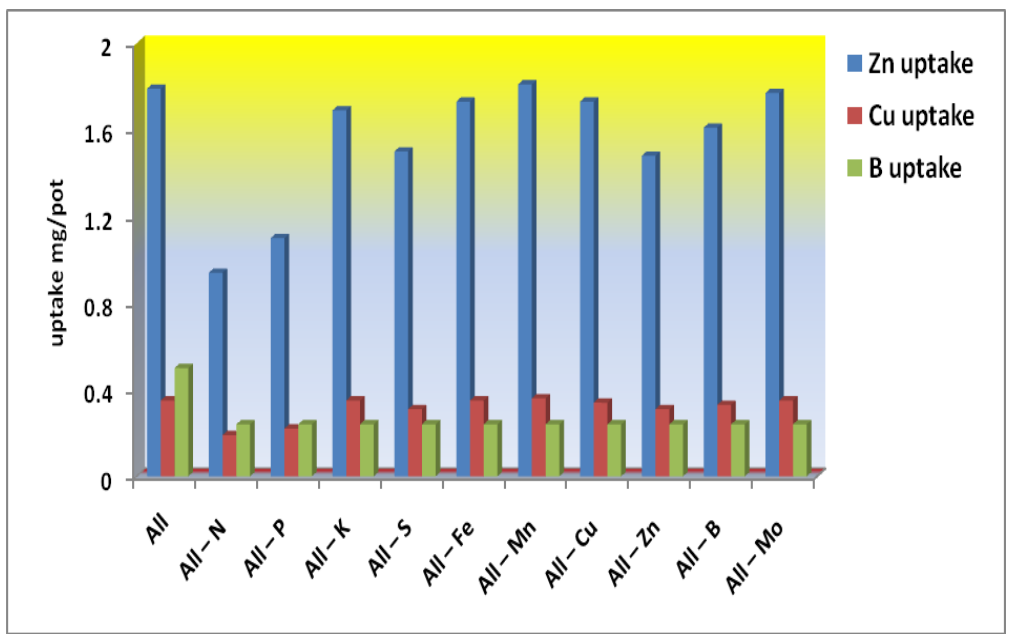

Fig.6 Wheat grain yields $(\mathrm{kg} / \mathrm{ha})$ of farmer's fields in relation to SSNM and farmers practice doses in Vertisol of Bemetara District

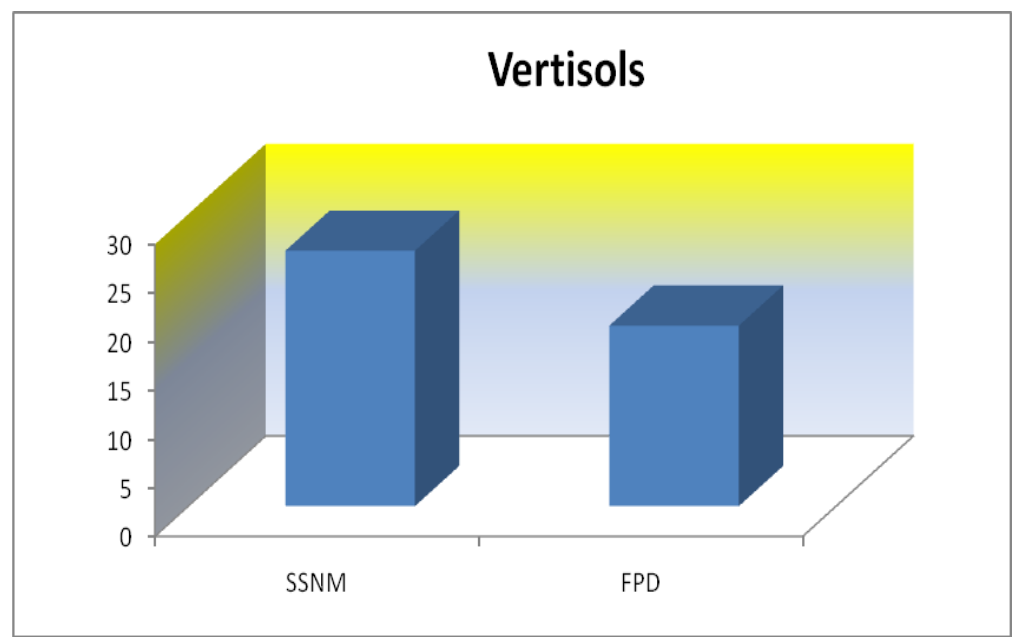


The mean total $\mathrm{Ca}, \mathrm{Mg}$ and $\mathrm{S}$ uptake by rice were significantly affected with application of different treatments. Omission of $\mathrm{N}, \mathrm{P}$ and $\mathrm{S}$ treatments caused significant reductions in the $\mathrm{Ca}, \mathrm{Mg}$ and $\mathrm{S}$ uptake in comparison to all other treatments including the SSNM treatment. Highest $\mathrm{Ca}$ uptake $(280 \mathrm{mg} / \mathrm{pot})$ was observed with the SSNM treatment receiving all the nutrients whereas the least Ca uptake was observed with $\mathrm{N}$ omission (160 mg/pot) followed by $\mathrm{P}$ omission (183 mg/pot) (Fig. 3).

Lowest $\mathrm{Mg}$ uptake was observed in the $\mathrm{N}$ omitted pot $(93 \mathrm{mg} / \mathrm{pot})$ followed by $\mathrm{P}$ omission (106 mg/pot) and $\mathrm{S}$ omission (138 $\mathrm{mg} / \mathrm{pot}$ ). Uptake of $\mathrm{Mg}$ in $\mathrm{K}, \mathrm{Cu}, \mathrm{Fe}, \mathrm{Mn}, \mathrm{Zn}$, $\mathrm{B}$, and Mo omitted pots and SSNM treatment were statistically at par with each other. Highest $S$ uptake $(76 \mathrm{mg} / \mathrm{pot})$ was observed with the SSNM treatment receiving all the nutrients and least $\mathrm{S}$ uptake $(37 \mathrm{mg} / \mathrm{pot})$ was observed with $\mathrm{N}$ omission treatment from SSNM. Omission of $\mathrm{P}$ recorded higher $\mathrm{S}$ uptake (43 mg/pot) than $\mathrm{N}$ omission. S uptake in $\mathrm{S}$ omitted pot was $59 \mathrm{mg} /$ pot and varied significantly.

The mean values on uptake of micronutrients by rice were significantly affected with application of different treatments. Omission of N, P and $\mathrm{S}$ caused lower uptake of Fe, Mn, $\mathrm{B}$ and $\mathrm{Cu}$ in different treatments. Highest $\mathrm{Fe}$, $\mathrm{Mn}, \mathrm{B}$, and $\mathrm{Cu}$ uptake were observed in the Mn omission followed by $(8.02 \mathrm{mg} / \mathrm{pot}) \mathrm{Mo}$ omission and (8.00 mg/pot) treatment receiving all the nutrients whereas the least uptakes were associated with $\mathrm{N}$ omission. Omission of $\mathrm{P}$ resulted in higher uptake than $\mathrm{N}$ omission. Micronutrients uptake in $\mathrm{Mn}, \mathrm{Cu}$, $\mathrm{K}$, Mo and B omitted pots were statistically at par with each other. Omission of N, P, S and $\mathrm{Zn}$ omitted treatments significantly reduced the uptake of $\mathrm{Zn}$ in different pots and maximum reduction in $\mathrm{Zn}$ uptake (0.94 $\mathrm{mg} / \mathrm{pot}$ ) was observed with $\mathrm{N}$ omission followed by $\mathrm{P}$ omission (1.10 $\mathrm{mg} / \mathrm{pot})$. Highest Zn uptake (1.79 $\mathrm{mg} / \mathrm{pot})$ was observed with the treatment receiving all the nutrients whereas the lowest uptake (0.94 $\mathrm{mg} / \mathrm{pot}$ ) was associated with $\mathrm{N}$ omission. The uptake of different nutrients by rice depended on dry matter production of the crop and hence results on uptake were almost identical with grain and straw yields of rice (Figs 4 and 5).

Based on the performance of rice crop during Kharif season, the nutrients identified as limiting nutrients were $\mathrm{N}, \mathrm{P}, \mathrm{S}, \mathrm{Zn}$ and $\mathrm{B}$. These nutrients were applied as per the following doses which are known as SSNM dose (as used in rice crop) and tested with wheat crop (GW-273). The SSNM doses were as $\mathrm{N}-150, \mathrm{P}_{2} \mathrm{O}_{5}-100, \mathrm{~K}_{2} \mathrm{O}-80, \mathrm{~S}-45, \mathrm{~B}-2$ and $\mathrm{Zn}-7.5 \mathrm{~kg} / \mathrm{ha}$. The farmer's fertilizer doses were applied at the rate of 80:58:38 $(\mathrm{N}$ : $\left.\mathrm{P}_{2} \mathrm{O}_{5}: \mathrm{K}_{2} \mathrm{O}\right) \mathrm{kg} / \mathrm{ha}$. The wheat grain yields of farmer's fields were higher in SSNM dose applied based on the yield limiting nutrients as compared to that of farmer's practice dose (Fig. 6). There was $29 \%$ increase in the wheat grain yield over farmer's practice dose. This testing confirmed that application of identified limiting nutrients as N, P, S, Zn and $\mathrm{B}$ nutrients in Vertisol were identified and must be applied for maximum crop yield.

\section{Acknowledgement}

The authors thankfully acknowledge to the IGKV authority for providing necessary facilities and financial support for conducting this research experiment in the Department of Soil Science and Agricultural chemistry, College of Agriculture, IGKV, Raipur.

\section{References}

Bhuiyan, N. I., Kabir, M. M., and Panaullah, G. M. 1986. Missing element trial: an effective tool for diagnosing most 
limiting nutritional problem for high yield in intensive wetland rice farming. In: Proceedings of National Symposium on Agriculture Research. 11-13 February 1986. Bangladesh Agricultural Research Council, Dhaka (Bangladesh) p.1.

Biswas, B. C., Sarkar, M. C., Tanwar, S. P. S., Das, S. and Kalwe, S. P. 2004. Sulphur deficiency in soils and crop response to fertilizer sulphur in India. Fertilizer News, 49 (10): 13-33.

Havlin, J. L., Tisdale, S. L., Beaton, J. D. and Nelson, W. L. 2007. Soil fertility and fertilizers - an introduction to nutrient management. Dorling Kindersley Pvt. Ltd., New Delhi, India, p. 175- 298.

Sakal, R. 2001. Efficient management of micronutrients for sustainablre crop production. Journal of the Indian Society of Soil Science, 49(4): 593-608.

Segda, Z., Haefele, S. M., Wopereis, M. C. S., Sedogo, M. P., and Guinko, S. 2005.Combining field and simulation studies to improve fertilizer recommendations for irrigated rice in Burkina Faso. Agronomy Journal, 97: 1429-1437

Sekhon, G. S. and Velayutham, M. 2002. Soil Fertility Evaluation. In: Fundamentals of Soil Science. Indian Society of Soil Science. New Delhi, p.419.
Sharma, R. P., Megh Singh and Sharma, J. P. 2003. Correlation studies on micronutrients vis-à-vis soil properties in some soils of Nagaur district in semiarid region of Rajsthan. Journal of the Indian Society of Soil Science, 51 (4): $522-527$.

Singh, M. V. 2000. Micro and secondary nutrients and pollutants research in India. A co-ordinated report for 19982000. AICRP micro and secondary nutrients and pollutant elements in soils and plants. Indian Institute of Soil Science, Bhopal, pp. 1-136.

Suriya Arunroj, D., Chaiyawat, P., Fukai, S., and Blamey, P.2000. Identification of nutrients limiting rice growth in soils of Northeast Thailand under water-limiting and non-limiting conditions. Plant Production Science, 3(4): 417-421.

Tiwari, K. N. 1990. Sulphur Research and Agricultural Production in Uttar Pradesh, India. Sulphur in Agriculture. The Sulphur Institute, Wasington, pp 14.

Yoshida, S. Forno, D. A. and Bhadrochalm, A. 1971. Zinc deficiency of rice plants on calcareous and neutral soils in the Phillipines. Soil Science and Plant Nutrition, 17: 83-87.

\section{How to cite this article:}

Neha Sahu, V. N. Mishra, L. K. Srivastava and Gaurav Jatav. 2017. Crop response based assessment of limiting nutrients using site specific nutrient management for yield maximization in Vertisols of Bemetara district of Chhattisgarh. Int.J.Curr.Microbiol.App.Sci. 6(6): 17841791. doi: https://doi.org/10.20546/ijcmas.2017.606.207 